\title{
Control Strategies for solar façade panels coupled with a Heat Pump and interacting with a District Heating Network
}

\author{
D.Rattazzi ${ }^{1}$, I. Rossi ${ }^{1}$, L. Magistri ${ }^{\text {I }}$, S.J.F..Erich ${ }^{2}$ \\ ${ }^{1}$ Thermochemical Power Group, University of Genoa, via Montallegro 1, 16145 Genoa, Italy \\ ${ }^{2} \mathrm{TNO}$, Anna van Buerenplein 1, 2509 The Hague, Netherlands
}

\begin{abstract}
This work aims to understand the potential of an innovative technology for solar energy harvesting in a District Heating Network (DHN). The considered technology is aesthetic solar façade thermal panel. In order to guarantee the temperatures required by a 3rd generation DHN (around $75^{\circ} \mathrm{C}$ ), a Heat Pump, using as cold source the heat from the panels, is necessary. It is worth noting that the coupling between façade panels and Heat Pump requires accurate evaluations. The optimum condition for the façade panels is to work at low temperatures (close to ambient or even below), while the Heat Pump reaches high Coefficient Of Performance (COP) when the temperature difference between hot and cold sources is minimized. In the first part of the study, a system model has been built using Matlab SIMULINK using results of tests on the panels already performed inside the H2020 ENVISION project. Different colours are considered. In the second part, a predictive mode-based strategy has been defined and tuned on the system in order to guarantee the best system performances in interaction with the DHN. This work will allow to understand whether this technology is feasible in the presented scenario and this layout can improve local energy exchange.
\end{abstract}

Keywords: District Heating Network; Control Strategy; Predictive Control.

\section{Nomenclature}

$C O P=$ Coefficient of performance

$D H N=$ District Heating Network

$E f f_{\text {evaporator }}=$ Evaporator efficacy

$H P=$ Heat Pump

$\dot{m}_{\text {panels }}=$ mass flow in panels circuit $[\mathrm{kg} / \mathrm{s}]$

$m G T=$ micro Gas Turbine
$M P C=$ Model Predictive Control

$P_{m G T}=$ mGT electrical power $[\mathrm{kW}]$

T DHNin = Inlet $\mathrm{HP}$ hot side $\left[{ }^{\circ} \mathrm{C}\right]$

T DHNout $=$ Outlet HP hot side $\left[{ }^{\circ} \mathrm{C}\right]$

T inPanels $=$ Façade panels inlet $\left[{ }^{\circ} \mathrm{C}\right]$

ToutPanels $=$ Façade panels outlet $\left[{ }^{\circ} \mathrm{C}\right]$

\section{Introduction}

The need of pollutant emission reduction requires an evolution in structure and interconnection of cities [1]. Particularly, the impact of the buildings on pollutant emissions is significant and strong adjustments must be considered to move towards a sustainable building profile. In these terms, the energy positive building framework, where buildings are able to produce energy and provide the difference to the grid has become more relevant [2]. This means to renovate the concept of the building itself - and an emerging way is to convert the building surfaces into active energy generator using renewable sources (e.g. solar radiation, wind) [3]. The conversion of the building is the first step, pushed forward by interconnecting these buildings into a smart grid environment, in which energy flows are redistributed according to local needs [4]. The H2020 ENVISION project focuses on these aspects, starting from buildings renovation to integration into existing smart grid. This last

ENVISION has received funding from the European Union's

Horizon 2020 research and innovation programme under grant agreement No 767180

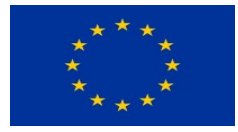


aspect is investigated by Thermochemical Power Group (TPG) at the Smart Polygeneration Microgrid (SPM) of Savona Campus of University of Genoa (UNIGE) [5]. One of the most critical aspects about the interconnection with a SPM consists into the system management, considering water temperature delivery, energy share between generators involved and storage management. In order to guarantee a balanced and consistent energy supply to the grid a proper control system is required: this problem is faced via implementation of Model Predictive Control (MPC) technique.

\section{System description}

At Savona Campus, the solar façade panel technology [6] will be tested. The technology consists of unglazed solar thermal panels that can be easily installed on a building vertical façade using a click-on method. The panels, meeting the different aesthetic requirements, are available in many different colours. The thermal energy provided by these panels has a different temperature depending on many different operating conditions. The District Heating Network (DHN) in Savona Campus requires a constant inlet temperature of $75^{\circ} \mathrm{C}$. Therefore, the direct coupling of the considered façade panels with the DHN is not possible: a Heat Pump (HP) bridges this temperature gap. The layout of the described system is reported in Figure 1.

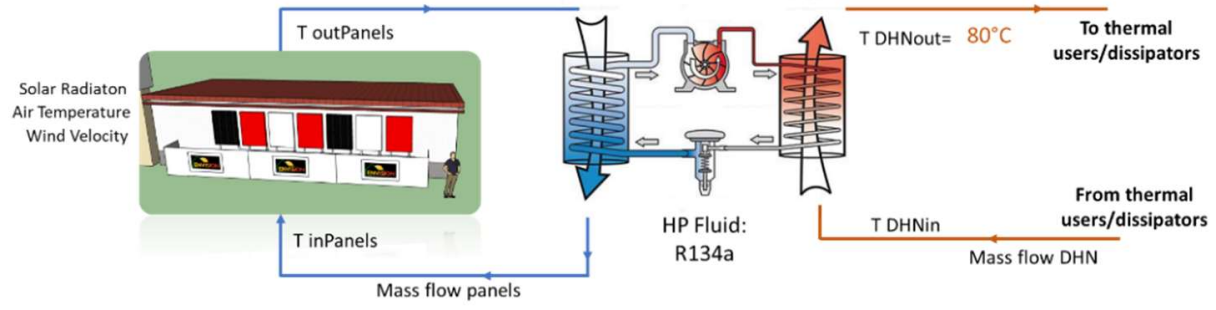

Figure 1 Heat Pump and Façade panels scheme

\subsection{Solar façade panels}

Currently, three different colours of solar façade panels are under investigation: white, red and black. An experimental correlation between the solar radiation on a vertical surface and the panel thermal efficiency (heat absorbed vs solar radiation) has been provided. Considering also ambient conditions (e.g. wind velocity, ambient temperature) [7]. The panels will be available in different sizes, for the prototype the dimensions are $2 \times 1$ meters. Considering the available building surface, 24 panels will be installed in Savona Campus ( 8 for each colour). In the façade solar panels flows a mixture of water and glycol in order to enhance the thermal exchange avoiding ice formation in the pipes. These panels have been modelled in Matlab/Simulink to test their simulated performances depending on the different ambient conditions actually measured on site at Savona Campus. Time-variant energy equations are computed inside the model, using as inputs the ambient parameters (such as solar radiation, air temperature and wind velocity) the energy absorbed by the fluid flowing through the panel pipes is provided. The importance of this model is also related to the evaluation of the best operational parameters in coupling with the Heat Pump. The considered parameters are the interconnection between the panels (series or parallel) and the mass flow rate through the panels. It is worth to specify that the series connection consists in single branches (i.e. White-Red-Black in series), interconnected in parallel each other (see Figure 2). 


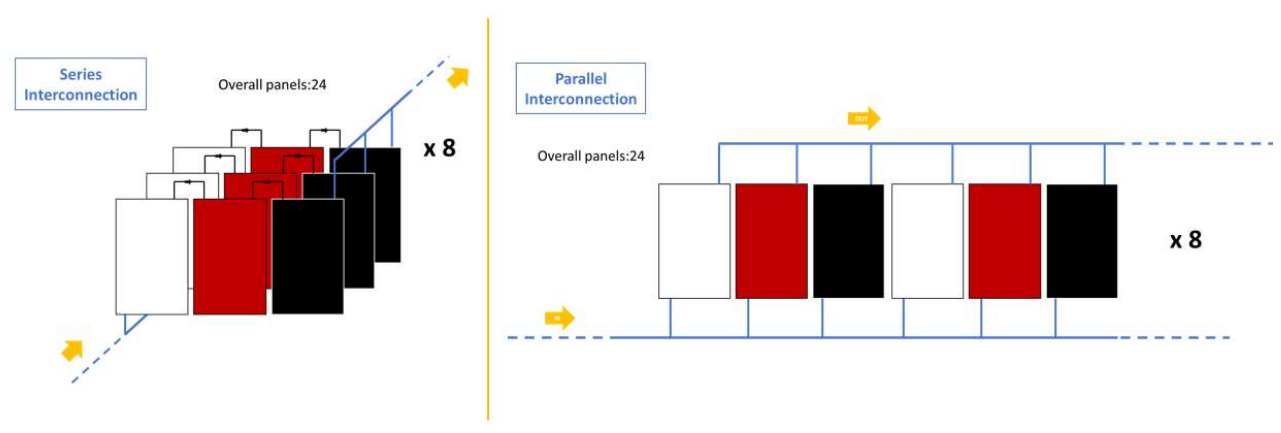

Figure 2 Series-parallel interconnection scheme

\subsection{Heat Pump}

The HP is installed in the system in order to provide heat at the constant temperature of $75^{\circ} \mathrm{C}$ degree to DHN. Considering the temperatures range, the HP working fluid is R134a. In order to maintain the desired temperature at the DHN inlet, a PI control is implemented to regulate the compressor power according to the flow temperature setpoint at the outlet of the hot side. The HP (water-to-water with volumetric compressor) and PI controller have been implemented in Matlab/Simulink environment [8]. Also in this case the governing equation of the model is the time-variant energy equations (implemented in evaporator and condenser block). The compressor chosen for this application is volumetric; its characteristics have been implemented in the code adding some physical delays in its operation. The main inputs for the Heat Pump model are the mass flow rate and the temperature in the inlet of evaporator (from the façade panels) and condenser (in return of DHN). It is worth underline that actually the PI controller is set to $80^{\circ} \mathrm{C}$ since an intermediate heat exchanger between the internal circuit and DHN will be installed, this allows to come over the thermal losses through the intermediate heat exchanger guaranteeing $75^{\circ} \mathrm{C}$ inside the real DHN circuit.

\section{Best system configuration}

One of the most critical aspects for coupling solar façade panels with a heat pump is to find the configuration that leads to the best overall system performance. To do that different schemes have been simulated varying the mass flow rate through the single panel (min: 0.01 $\mathrm{kg} / \mathrm{s}$, max: $0.05 \mathrm{~kg} / \mathrm{s}$ as available in literature for the thermal and PV thermal panels [9][10]) and the series or parallel configuration. The tests have been performed supposing a constant heat requirement by the DHN at the constant temperature of $75^{\circ} \mathrm{C}$, this aspect allows to minimize the changing parameters focusing on the façade panel performances). In this scenario, the parameter that allows the system evaluation is the COP (Coefficient Of Performance) i.e. the index of efficiency of the HP. Considering the compressor power absorption of the HP as the only term of significant consumption in the system, the best system configuration leads to the lowest power consumption by the compressor. This consideration suggests that the most important parameter is the quantity of heat produced by the façade panels and not just the temperature reached by the water-glycol mixture. This consideration leads to a compromise between mass flow rate through the panels and high temperature at the panels outlet. Simulation for different scenarios have been performed in Simulink environment considering two representative solar days for cold and hot season. 

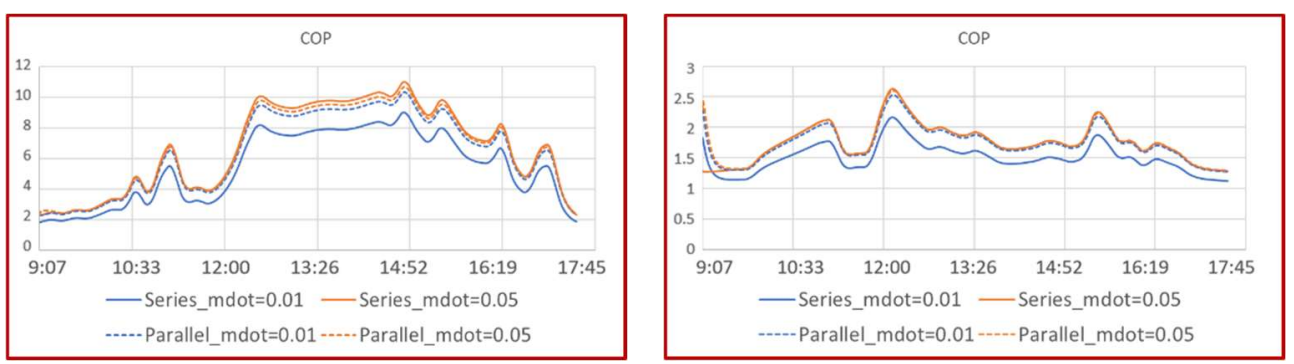

Figure $3 \mathrm{COP}$ for different configurations during a daily solar period in cold (left) and hot season (right)

As it can be seen in Figure 3 the highest COP values are reached for the interconnection in series with the highest value of mass flow rate through the panels in both periods. The heat provided by the panels is given by temperature and mass flow rate. By increasing the mass flow rate, the temperature at the outlet of the panels decreases. In addition, an increase of mass flow rate leads to a higher temperature at the inlet of façade panels circuit because the same heat absorption in the HP evaporator is achieved with a lower temperature difference through the evaporator heat exchanger due to the total mass flow rate increasing in the panels circuit (Eq.1). This aspect leads to a lower panel efficiency and therefore lower heat absorption by the heat pump.

$$
Q_{\text {evaporator }}=\dot{m}_{\text {Panels }} * c_{\text {p }\left(\text { glycol }_{\text {water }}\right)} *\left(T_{\text {outPanels }}-T_{\text {inPanels }}\right) * E f f_{\text {evaporator }}
$$

The parallel configuration at one side guarantees a higher value for the total mass flow rate but on the other sides does not lead to high temperatures as the series configuration does (see Figure 4).

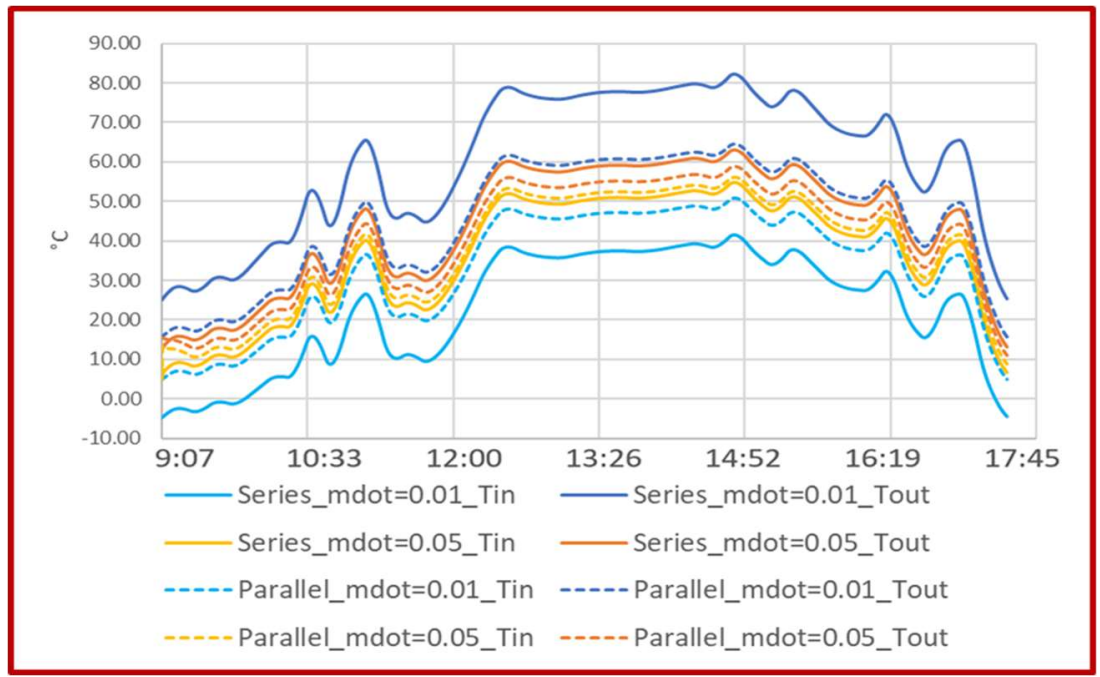

Figure 4 Inlet and Outlet temperature for the panels in different configurations during hot season

Therefore, considering the big number of parameters affecting the system behaviour the reliable optimum conditions can only be discovered with an accurate model that will be validated using the upcoming test campaign on the panels. In conclusion, it can be stated that, considering the model simulations, the configuration considered from now on is the one with the max mass flow per panel $(0.05 \mathrm{~kg} / \mathrm{s})$ and a series interconnection between the panels. Table 1 reports a schematic summary of the obtained results. 
Table 1 Main results summary

\begin{tabular}{|l|l|l|l|l|}
\cline { 2 - 5 } \multicolumn{1}{c|}{} & $\begin{array}{l}\text { Series } \\
\text { interconnection }\end{array}$ & $\begin{array}{l}\text { Parallel } \\
\text { interconnection }\end{array}$ & $\begin{array}{l}\text { Low mass flow } \\
\text { rate per panel }\end{array}$ & $\begin{array}{l}\text { High mass flow } \\
\text { rate per panel }\end{array}$ \\
\hline Outlet temperature & $\begin{array}{l}\text { High } \\
\text { temperatures }\end{array}$ & $\begin{array}{l}\text { Low } \\
\text { temperatures }\end{array}$ & $\begin{array}{l}\text { High } \\
\text { temperatures }\end{array}$ & Low temperatures \\
\hline Single panel mass flow rate & - & - & Decreases & Increases \\
\hline $\begin{array}{l}\text { Overall circuit mass flow } \\
\text { rate }\end{array}$ & Decreases & Increases & Decreases & Increases \\
\hline
\end{tabular}

\section{Case Study}

The definition on the case study is based on the foreseen application. The creation of energy positive buildings without the capability to operate into a multi commodities environment cannot be considered. Therefore, it has been considered the afore mentioned system composed by panels and HP as integrated into a smart grid where other local generators provide energy. This first step aims to integrate the panels and the HP with a CHP micro gas turbine (mGT) - and governing the energy share via an MPC.

\subsection{MPC description}

The MPC is a control-based architecture that utilizes an explicit model to predict the future response of a system. This is achieved by a prediction horizon based on preceding and future actuator commands. Implemented for many applications [11], the application of MPC in the field of the smart grid has risen consistently in last decade [12].

\subsection{MPC implementation and results}

The implemented MPC strategy consists in the control of the mGT and the Heat Pump in order to match the electrical and thermal loads respecting the intrinsic limitations of the system. The setpoints are given based on the loads applied in Matlab/Simulink representing two days for hot and cold season. The controller gives the electrical power required from the mGT $\left(\mathrm{P}_{\mathrm{mGT}}\right)$ and the heat required from the HP $\left(\mathrm{Q}_{\mathrm{cond}}\right)$ as outputs through a predictive calculation developed on a state-space system (representing the real model) implemented inside the controller. The mGT model through correlation curves elaborates the thermal power generation related to the electrical one asked by the controller, providing to the system both energy sources. The MPC regulates the heat provided by the heat pump acting on the mass flow rate from the DHN, while the PI control inside the HP guarantees the desired outlet temperature. The temperature from the façade panels circuit is implemented as a measured disturbance since it is a parameter that affects the HP performances without that it can be controlled by the MPC.

The relevance of thermal loads has been considered more significant than the electrical one since that in this configuration no thermal storages are considered. Therefore, the MPC weights have been tuned in respect of these system requirements. The results provided by the simulation on a summer day are reported in the following figures. The summer period is reported as significative example, since the period where the façade panels are supposed to have a stronger impact on the system. The thermal demand is well covered with the chosen controller despite the electric one is basically a consequence of the thermal management (Figure 5 and Figure 7). The use of a thermal storage can be considered to guarantee a better covering for both demands. Figure 6 provides a detailed view about the thermal production considering separately the mGT and the Heat Pump. Figure 8 shows the management provided by the MPC in order to guarantee the energy productions showed in Figure 6 . The parameters controlled by the MPC are $\mathrm{P}_{\mathrm{mGT}}$ for $\mathrm{mGT}$ and $\mathrm{Q}_{\text {cond }}$ for the HP. The mGT size chosen is of $100 \mathrm{kWe}$ and has a minimum cut-off of $20 \mathrm{~kW}$, while the HP has a maximum heat power of $20 \mathrm{kWth}$ : Figure 8 confirm how the MPC respects these constraints implemented in the controller. 


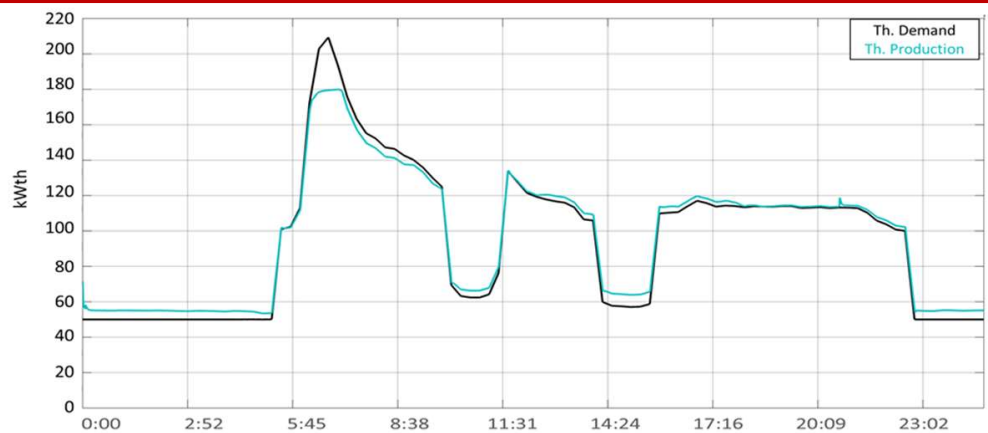

Figure 5 Overall thermal management during an hot season day

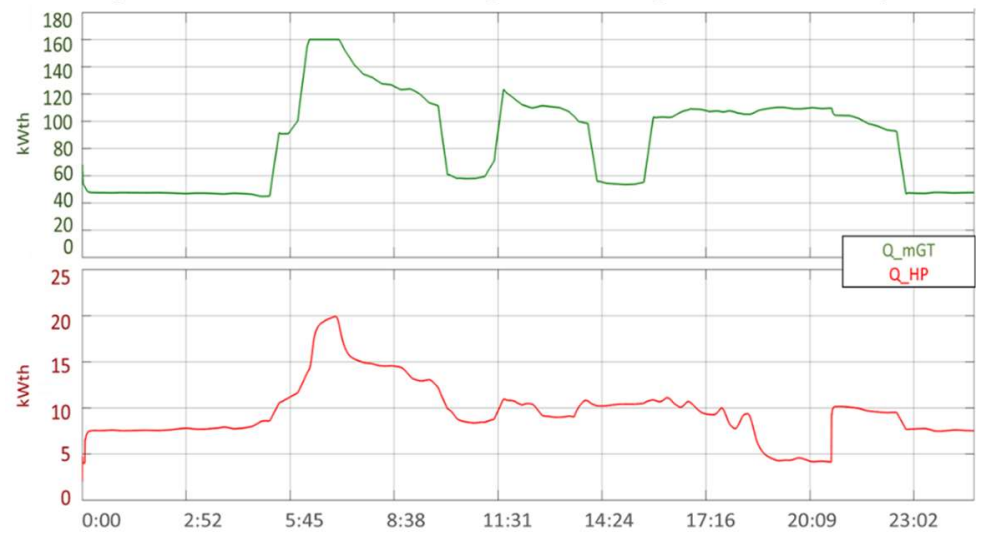

Figure $6 \mathrm{mGT}$ (top) and Heat Pump (bottom) thermal production during a hot season day

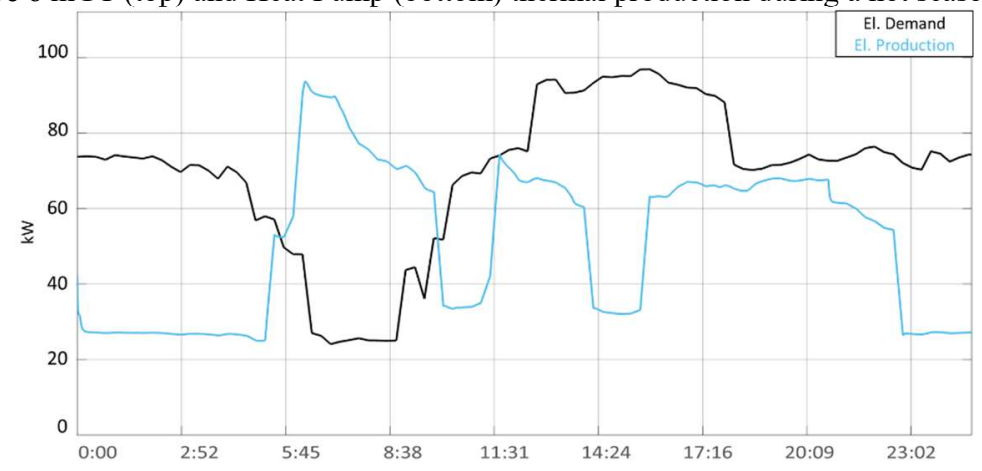

Figure 7 Electrical management during a hot season day

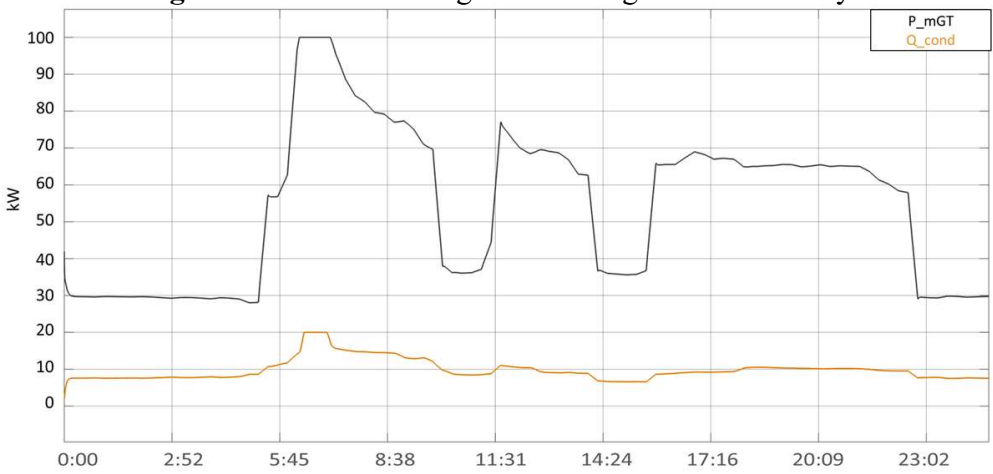

Figure 8 MPC control on $\mathrm{P}_{\mathrm{mGT}}$ (black) and $\mathrm{Q}_{\text {cond }}$ (orange) 


\section{Conclusions}

In this work the solar façade panels and HP models have been implemented and integrated each other. Different scenarios (considering mass flow through the panels and different interconnections between the panels) have been simulated in order to choose the configuration that leads to the best system performance. Subsequently an MPC control has been implemented in order to properly manage the system (in its best configuration) considering the energy requests from the DHN. It is worth noting that the consumption related water-glycol pump (inside the panels circuit) has been neglected as the pressure drop over the panels has not been evaluated in the preliminary tests. A first demo will be installed in Savona Campus starting from June 2019 that will allow pressure drops to be experimentally determined and are expected to be negligible. In the near future it will be interesting to perform a more detailed system management that considers also economic aspects: energy cost along the day will be implemented and a cost function to minimize will be inserted in the control strategy. A thermal storage will be experimentally installed in order to make it more independent of thermal and electrical demands, giving more flexibility to the whole system.

\section{References}

[1] M. Arnaudo, O.A. Zaalouk, M. Topel, B. Laumert, "Techno-economic analysis of integrated energy systems at urban district level-a Swedish case study", Energy Procedia, 2018

[2] Y. Luo, L. Zhang, M. Bozlar, Z. Liu, H. Guo, F. Meggers, "Active building envelope systems toward renewable and sustainable energy", Renewable and sustainable energy reviews 104 (470-491), 2019

[3] V.S.K.V. Harish, A. Kumar, "A review on modelling and simulation of building energy systems", Renewable and sustainable energy reviews 56 (1272-1292), 2016

[4] A. Zajacs, A. Borodinecs "Assessment of development scenarios of district heating systems", Sustainable cities and society 48, 2019

[5] http://www.energia2020.unige.it/spm/, last access 29/04/2019

[6] http://www.energy-envision.eu/, last access 30/04/2019

[7] Private communication inside ENVISION consortium

[8] R.Sangi, P. Jahangiri, D. Müller; "A combined moving boundary and discretized approach for dynamic modeling and simulation of geothermal heat pump systems", Thermal Science and Engineering Progress

Volume 9, March 2019, Pages 215-234

[9] A.L. Abdullah, S. Misha, N. Tamaldin, M.A.M. Rosli, F.A. Sachit, "Photovoltaic Thermal /Solar (PVT) Collector (PVT) System Based on Fluid Absorber Design: A Review", Journal of Advanced Research in Fluid Mechanics and Thermal Sciences 48 (196-208), 2018

[10] T. Dembeck-Kerekes, Jamie P. Fine, J. Friedman, S.B. Dworkin, J.J. McArthur, "Performance of variable flow rates for photovoltaic-thermal collectors and the determination of optimal flow rates", Solar Energy 182 (148-160), 2019

[11] W.R. Sultana, S. K. Sahoo, S. Sukchai, S.Yamuna, D.Venkatesh "A review on state of art development of model predictive control for renewable energy applications", Renewable and sustainable energy reviews 76 (391-406), 2017

[12] I. Rossi, L. Banta, A. Cuneo, M. L. Ferrari, A. N. Traverso, A. Traverso, "Real-time management solutions for a smart polygeneration microgrid", En Conv Man, vol 112, 2016 